\section{The Politics of Smoking: Findings or Agendas?}

\author{
by Cathy A. Enz, Ph.D., Lewis G. Schaeneman Jr. Professor of Innovation \\ \& Dynamic Management; David L. Corsun, doctoral candidate; Cheri A. \\ Young, doctoral candidate. The authors gratefully acknowledge the helpful \\ comments of Professor Sheryl Kimes.
}

The April 1996 issue of the Cornell Hotel and Restaurant Administration Quarterly presented our findings of a study on consumer dining attitudes and behavior after passage of the New York City Smoke-Free-Air Act. Since that time the study has prompted both public praise and criticism. While some have used this preliminary study to encourage legislators to enact smoking bans, others have prepared detailed negative critiques. The Advocacy Institute, for instance, has used the study to support its agenda of encouraging the passage of smoke-free policies in local communities. In contrast, the National Smokers Alliance (an advocacy group for the tobacco industry) commissioned a critique from the Evans Group, a consulting firm whose president, Michael Evans, is a clinical (teaching) professor at Northwestern University.'

While it is the case in the world of political debate that different sides on an issue use persuasion and may even hire consultants to help show the merits of their position, the best way to gather and use information on important social issues is to conduct a number of research studies. All studies have limitations, and the more research conducted the greater the value of the resulting accumulated knowledge. We noted in our April 1996 paper and now restate that this study is a first attempt to compile consumer-behavior data. We stated, "The conclusions drawn from these data should be treated as preliminary. Similar results based on the collection of additional data in the future would strengthen the conclusions drawn herein."

We are pleased to have been among the first to open this area for scientific inquiry, but feel that the recent critique by the consultant to the National

\footnotetext{
${ }^{1}$ Many restaurant associations have received copies of the Evans Group critique. The Empire State Restaurant Association also requested a review from Coopers \& Lybrand. The full text of both documents can be found on the world wide web at ahttp://hotelschool.cornell.edus

'See: David Corsun, Cheri Young, and Cathy Enz, "Should NYC's Restaurateurs Lighten Up?," Cormell Hotel and Restanrant Administration Quarterly, Vol. 37, No. 2 (April 1996), p. 26.
}

Smokers Alliance, distributed widely to restaurant associations, may confuse concerned restaurateurs. While differences of opinion are always present on sensitive issues, the Evans Group critique attempts to discredit the study and distort the contribution this research can make to public debate. We are concerned that restaurateurs may be lost in the smoke of rhetoric and confusion as they try to discern whether this form of legislation will have a positive or negative impact on their businesses. In this paper we review briefly the major findings of our study and provide a specific rejoinder to the Evans Group critique.

\section{Summary of the Study}

Four months after passage of the smoking ban we randomly surveyed a total of 389 patrons of New York City restaurants concerning any changes in their dining behavior, their attitudes toward and tolerance of smoking, spending patterns, and feelings about government legislation of smoking. Data were collected from patrons as they exited a randomly stratified sample of Manhattan restaurants during both lunch and dinner hours on each of the seven days of the week during August 13-20, 1995. Restaurant locations reflected inexpensive, moderate, and expensive priced restaurants and those with four different types of accommodations, namely: totally smoke-free, smoking at the bar, smoking allowed at dining tables, and smoking throughout. Extra effort was made to locate restaurants that permitted smoking for inclusion in this study because after contacting 100 randomly selected restaurants, we had not found any restaurants that allowed smoking at their dining tables. A supplemental list of restaurants was compiled using The Smoker's Guide to Dining Out in New York City and The Insider's Guide to Smoking and Dining in Manhattan to locate restaurants with these accommodations. We didn't ask respondents whether they smoked in advance of surveying them. Of the 389 patrons who volunteered to participate in our survey, 34.4 percent were smokers and 65.6 percent were nonsmokers. A total of 71.8 percent were New York City residents, 21.2 percent were from the metro area, and only 7 percent reported a residence outside of the NYC area.

We undertook this study because there was a void in the smokinglegislation literature in that no studies had been conducted in NYC of actual consumer behavior. The study's purpose was to explore consumer attitudes toward smoking and the act, the degree to which the act was violated by smokers, how the law was being enforced, and changes in consumer dining behavior. In addition, we devised a classification scheme to avoid the tendency to obscure differences within the smoker and nonsmoker consumer 
groups. In summary, the major findings were as follows.

\section{Dining Behavior}

- 37.6 percent of smokers reported that they had dined out less frequently since passage of the act.

- 59.4 percent of smokers reported seeking out smoking-permitted restaurants.

- 16.5 percent of nonsmokers reported that they had dined out more frequently since passage of the act.

- 36.5 percent of nonsmokers reported avoiding smoking-permitted restaurants.

Consumer Spending Patterns

- Smokers reported spending \$23.91 and nonsmokers reported spending $\$ 21.74$ per meal dining out.

- Smokers reported dining out 6.6 times per week and nonsmokers said they dined out 5.6 times.

\section{Enforcement and Violation}

- 41 percent of smokers reported having smoked in a smoke-free area in violation of the act.

- 54.6 percent of nonsmokers reported having seen someone smoke in a smoke-free area in violation of the act.

\section{Attitudes Toward Smoking and} the Act

- 12.7 percent of smokers and 76.7 percent of nonsmokers favor the act.

- 61.2 percent of smokers and 91.3 percent of nonsmokers believe second-hand smoke is hazardous.

\section{Profile Categories of Smokers and} Nonsmokers. We classified respondents into five profile types, three for smokers and two for nonsmokers. Smokers were grouped as violators, avoiders, and adapters based on their adherence to the law and avoidance of smoke-free restaurants. We identified two types of nonsmokers based on whether they were smoke sensitive (and thus avoided smoke-permitting restaurants) or smoke tolerant.

- 37 percent of smokers do not violate the act or avoid smoke-free restaurants.
- Nonsmokers and smokers who are adapting to the act account for 84 percent of the general population.

\section{The Heart of the Controversy}

The policy issue for the restaurant industry rests on the question of whether smoke-free legislation will result in net revenue declines for local restaurant owners-an important issue but not the focus of our study. Several studies have examined economic issues directly and found smoke-free ordinances have not led to decreased sales revenue among restaurants, although these studies have been critiqued. ${ }^{3}$ While our study was not on economic impact, our paper did present important implications for the restaurant industry based on the behavior reported by our respondents, and we offered advice to the practitioner audience of the Cornell Quarterly. A few excerpts show what we suggest:

“... nonsmokers who are smokesensitive are dining out more than before. This consumer group is the largest, and spends the most overall."

"The act has had a decidedly negative impact on some restaurants, particularly those restaurants whose smokers come less frequently but which have not realized a counterbalancing increase in the attendance and spending of nonsmokers. Conversely, some restaurants are probably benefiting from the smoke-sensitive nonsmokers' increased dining frequency. Still other restaurants remain relatively unaffected with regard to their sales."

"Our findings suggest that New York City's restaurateurs should 'lighten up' instead of trying to cater to

${ }^{3}$ The following studies have found no loss of revenue due to smoke-free policies: "The Effect of Ordinances Requiring Smoke-Free Restaurants on Restaurant Sales," American Journal of Public Health, July 1994;"Assessment of the Impact of a 100\% Smoke-Free Ordinance on Restaurant Sales-West Lake Hills, Texas," Morbidity and Mortality Weekly Report, Centers for Disease Control and Prevention, May 19, 1995. A critique of the studies written by Glantz and Smith was prepared by Coopers \& Lybrand in March 1996. those who insist on 'lighting up.' The data indicate it is unwise to try to please everyone. Lightening up may just mean pleasing the nonsmoking majority and making more money in the long run."

"Ultimately, smoke-free legislation is likely to have a positive impact on restaurant-industry revenues."

The controversy in the wake of this article flows from how various advocacy groups have used our study. The Advocacy Institute prepared a strategy document advising those who support smoke-free legislation to use the study and other studies to refute claims that restaurants' clean-indoor-air policies harm restaurants economically. The National Smokers Alliance sought out the Evans Consulting Group to critique the study. As researchers, we do not side with any group, and our project was not funded by an advocacy group. Clearly we cannot control how others choose to use the study. This response to the Evans Group critique was prepared because it is important for the many restaurant associations and operators to understand the findings of our study. The rest of this paper is our response to the Evans Group.

\section{Critique and Rejoinder}

The Evans Consulting Group review of our Cornell Quarterly article suggested several major criticisms which are presented below with our responses. The president of the Evans Group begins the critique as follows:

"The Cornell Survey purports to show that the smoking ban on restaurants in New York City will not reduce restaurant revenues. That conclusion is invalid for several reasons.

1. "The Cornell Survey is seriously incomplete, because it does not measure the change in the number of times per week that smokers and nonsmokers dined out before and after the ban, or the amount spent per meal before and after."

Our study is not invalid because we studied something other than what the 
Evans Group would have us study. The goal of any well-designed survey is to answer the questions of interest to the researchers conducting the study. A reasonable question is whether our study correctly investigated the questions we sought to answer. As noted earlier here and in our original article, the purpose of our study was to "explore the actual impact of the act on consumer behavior" (p. 26). The data presented in our article (see Exhibits 3, 5 , and 6) show the results of investigating this question.

The Evans Group wishes we had studied the economic impact of the bill using pre- and post-ban data. It concludes that it could not answer its questions with our data. We encourage researchers to conduct studies on the topic of economic impact. Some existing work in this area is already available as noted earlier.

2. "The number of nonsmokers who spent less time dining out after the ban was imposed is slightly higher than the number of nonsmokers who spent more time dining out. We have interpreted this finding to mean that the amount spent per meal by nonsmokers did not increase after the ban. Using that assumption and incorporating the other parameters reported in the Cornell Survey, we find that the imposition of a smoking ban in New York City will always result in a decline in restaurant revenues."

We are puzzled that the Evans Group finds that the smoking ban will always result in a decline in restaurant revenues without having collected data on the economic impact of the act. The reviewer argues in criticizing our work that the only way to assess the economic impact of the ban is by conducting a pre- and post-ban study. Neither the Evans Group nor we conducted such a study.

3. "Using the other parameters of the Cornell Survey and making reasonable assumptions about proportionality, we calculate that their survey would have shown a 9-percent decline in restaurant revenues if the relevant before-and-after data had been collected."

For "purposes of illustration," the Evans Group creates hypothetical preban numbers and then creates post-ban numbers to "show" how revenues would decline. We will not enter the realm of critiquing the use of "illustrative" hypothetical numbers although we find this practice odd, but several times the reviewer points to our data in making calculations while ignoring it at other times.

The reviewer notes, "In order to show how the calculations should have been performed, we start with the Cornell Survey finding that smokers are 34.4 percent of the Manhattan restaurant-going population and nonsmokers are 65.6 percent."

The percentages of respondents in our study is not a finding, but a sample characteristic. We did not find that smokers are 34.4 percent of the Manhattan restaurant-going population. It is not reasonable to assume, simply because we surveyed 134 smokers who constitute 34.4 percent of our total sample, that this percentage is the proportion of smokers in the general population. We randomly asked consumers to respond to our survey, and 34.4 percent of those voluntary respondents were smokers. We did not wish to restrict participation on the basis of whether a consumer smoked. As a result, more smokers are represented in our sample than are present in the population ( 26 percent) because they took the time to voluntarily respond to our survey. Remember, we did not ask about smoking preference as a condition for participation in our survey. This information about sampling can be found on pages $27-28$ of our article. Future studies might wish to explore the interesting question of what percentage of restaurant diners are smokers and what percentage are nonsmokers. We used general population information as a logical first start.

The Evans group critique continues:
"For purposes of illustration, assume that before the ban, smokers dined out an average of 7 times per week and spent an average of $\$ 25.00$ per meal, and after the ban, they dined out an average of 6 times per week and spend an average of $\$ 20.00$ per meal."

We would like to suggest that the Evans Group start with the Cornell Survey findings in building their postban illustration. We found that after the ban, smokers dined out an average of 6.6 times per week, so why does the reviewer use 6 ? We found that the amount spent on average per meal was $\$ 23.91$ for smokers, so why does the reviewer use $\$ 20.00$ ? The basic difference between the Evans illustration and the one we conducted in response to the commentary is that the Evans Group rounded the dining figures from 6.6 to 6 for smokers and from 5.59 to 5 for nonsmokers.

The critique changes the number of dining-out occasions from 6.6 to 6 for smokers and from 5.59 to 5 for non smokers; and it changes the amount spent on average per meal for smokers to $\$ 20.00$ from $\$ 23.91$ and the average spending for nonsmokers to $\$ 22.00$ instead of $\$ 21.74$.

"We find that the imposition of a smoking ban in New York City will always result in a decline in restaurant revenues."

The Evans Group conducted an analysis based on numbers it created to reach the conclusion of economic decline. We conducted this "illustrative" exercise using our study data and found the opposite conclusion. No justification is provided by the Evans Group for its pre-ban numbers. The Evans Group ignores our post-ban data on average spending per meal and the number of times dining out per week reported by our respondents. It chooses to use the percentage of randomly selected smokers and nonsmokers who agreed to participate in our study instead of the percentage of these two groups represented in the population at large. We seriously question this, but 
have created a "case one" with general population figures, and a "case two" with sample figures. In the accompanying box we show the Evans Group's calculations from which it concludes that total restaurant revenues have declined by $\$ 5.14$ per person per week. While it was not the intent of our study to examine this issue using pre-ban assumptions, if we use Evans Group assumptions pre-ban, Cornell data post-ban, and two different approaches to population percentages (ours in case one and the Evans Group's in case two), we conclude in both cases that total restaurant revenues have increased-in case one by $\$ 11.44$ and in case two $\$ 8.21$ per person per week.

The figures presented in the accompanying box fail to support the Evans Group claim that imposing a smoking ban will always result in a decline in restaurant revenues.

Where does the truth lie? The truth is that no debate of this kind should be conducted by assumption and assertion. The Evans Group assumes postban spending figures that are at variance with the data we collected and then states, "We find that the imposition of a smoking ban in NYC will always result in a decline in restaurant revenues." Using the Evans Group assumptions for pre-ban spending we find the exact opposite. If we were trying to prove an opinion, we might follow their lead and conclude that the imposition of a smoking ban in New York City will always result in an increase in restaurant revenues. We do not make this conclusion, but only show how easy it is to achieve a conclusion based on "reasonable" but unsupported assumptions.

4. The Evans Group states that there are major questionable assumptions and methodological errors in the Cornell Survey, presenting five points that we address in the order each was presented.

A. "The choice of Manhattan, instead of all of New York City, is convenient but nonetheless could impart a

\section{Illustrative Examples}

\section{Evans Group Figures}
Before the Ban
$(.344)(7)(\$ 25)+$
$(.656)(5)(\$ 20)=\$ 125.80$
After the Ban
$(.344)(6)(\$ 20)+$
$(.656)(5.5)(\$ 22)=\$ 120.66$

Conclusion-Net revenue loss of $\$ 5.14$

$.344=$ Percentage of voluntary respondents in Cornell Study who smoke

$.656=$ Percentage of voluntary respondents in Cornell Study who do not smoke

$7.0=$ Assumed average number of meals per week by smokers, pre act

$6.0=$ Assumed average number of meals per week by smokers, post act

$5.0=$ Assumed average number of meals per week by nonsmokers, pre act

$5.5=$ Assumed average number of meals per week by nonsmokers, post act

$\$ 25.00=$ Assumed average amount spent per meal by smokers, pre act

$\$ 20.00=$ Assumed average amount spent per meal by smokers, post act

$\$ 20.00=$ Assumed average amount spent per meal by nonsmokers, pre act

$\$ 22.00$ = Assumed average amount spent per meal by nonsmokers, post act

\section{Cornell Figures}

$\begin{array}{ll}\begin{array}{l}\text { Case One-Using General Population Figures } \\ \text { Before the Ban }\end{array} & \text { After the Ban } \\ (.26)(7)(\$ 25)+ & (.26)(6.6)(\$ 23.91)+ \\ (.74)(5)(\$ 20)=\$ 119.50 & (.74)(5.59)(\$ 21.74)=\$ 130.94\end{array}$

Conclusion-Net revenue gain of $\$ 11.44$

Case Two-Using Cornell Study Figures*

$\begin{array}{ll}\text { Before the Ban } & \text { After the Ban } \\ (.344)(7)(\$ 25)+ & (.344)(6.6)(\$ 23.91)+ \\ (.656)(5)(\$ 20)=\$ 125.80 & (.656)(5.59)(\$ 21.74)=\$ 134.01\end{array}$

Conclusion-Net revenue gain of $\$ 8.21$

$.260=$ Percentage of smokers in the general population

$.740=$ Percentage of nonsmokers in the general population

$.344=$ Percentage of respondents in Cornell Study who smoke

$.656=$ Percentage of respondents in Cornell Study who do not smoke

$7.0=$ Used Evans pre-ban assumptions

$6.0=$ Cornell Study average number of meals per week by smokers, post act

$5.0=$ Used Evans pre-act assumptions

$5.5=$ Cornell Study average number of meals per week by nonsmokers, post act

$\$ 25=$ Used Evans pre-act assumptions

$\$ 23.91$ = Cornell Study average amount spent per meal by smokers, post act

$\$ 20.00=$ Used Evans pre-act assumptions

$\$ 21.74=$ Cornell Study average amount per meal by nonsmokers, post act

" In a recent letter to one of the authors, Michael Evans, president of the Evans Group, argues that since 34.4 percent of the respondents said they were smokers, this should be the number used in calculations regardless of whether the population at large has a smaller percentage of smokers. We have used this figure in Case 2 because Evans argues, "I used the figure that 34.4 percent of the survey participants are smokers because that is your figure. In denying this, you are essentially throwing away the part of your results that you didn't like, and only keeping the parts you did like." The results are the same, a net gain in revenue. 
bias to the results. Restaurants in the outer boroughs are more likely to lose smoking patrons to dining facilities outside the city limits...."

Manhattan was chosen over the other boroughs because of its variety of restaurants and preponderance of business diners and commuters. It is an intriguing empirical question for future research to determine whether restaurants in the outer boroughs are, indeed, more likely to lose smoking patrons to dining facilities outside the city limits. It would also be useful to know if nonsmoking residents of the NYC metro area are dining more frequently in the city as a result of the smoking ban. Clearly a great deal more can be learned in subsequent studies.

B. "The choice of April and August as comparative dates may also bias results. Many New York residentsespecially those in Manhattan-tend to go on vacation during the month of August. Also, tourists to Manhattan during August tend to be family groups rather than business visitors."

A total of 93 percent of the sample are residents of the NYC metro area, the vast majority of whom live in NYC (71.8 percent). A total of 7 percent fall in the "other" category, which may include vacationers or business travelers from out of town. Clearly the sample more than adequately represents New York residents and is not biased toward tourists, given their small representation in this study. Data were gathered at lunch and dinner hours and in restaurants ranging in price from inexpensive to expensive. See Exhibit 2 , p. 28 , for all demographic data.

C. "Gains in people dining out and increased spending in post-ban Manhattan are probably due to the boom in the stock market and are associated with those employed in the brokerage industry eating out more than those in other industries."

While these speculations can hardly be evidence of our "unsubstantiated assumptions" in any event, we note a careful sampling process in which we surveyed respondents at 19 different restaurant locations throughout Manhattan (not just the financial district) and at both lunch and dinner periods. See pages $27-28$ for a detailed discussion of our sampling procedure.

D. "Since nonsmokers said they dined outside NYC more frequently, this indicates that smoke-free restaurants were not as important to them as one would expect. Since only around 15 percent of nonsmokers are dining out more frequently, this behavior may be due to economic factors and not the ban."

It is the case that 31.4 percent of the nonsmokers in our sample said they dined outside of NYC more frequently since the ban was in effect in April. As easily as one might reach the conclusion the reviewer reaches about the importance of smoke-free environments to nonsmokers, one could speculate that this behavior is due to the summer vacations and weekend homes of NYC residents. However, we do not have data on why this group of nonsmokers is dining outside NYC. It is also the case that 36.5 percent of nonsmokers report increases in avoidance of smoking-permitted restaurants. A total of 34.4 percent of smoke-sensitive nonsmokers report dining out more frequently since the act. This group of nonsmokers appears to be dining out far more frequently than the other type of nonsmokers, making the impact of economic factors less likely than the impact of smoking bans.

E. "The authors emphasize the fact that $34.4 \%$ of 'smoke-sensitive diners' are now dining out more frequently (Exhibit 7). However, since Exhibit 3 states that $31.4 \%$ of nonsmokers are dining more frequently outside NYC, that $34.4 \%$ may be composed almost exclusively of diners who chose to patronize restaurants outside the city, rather than smoke-free restaurants within the city."

Here the reviewer has posed an empirical question that our data do permit us to answer. The data indicate that only 16.7 percent of smoke- sensitive nonsmokers dine outside of NYC more frequently than they did prior to April. The nonsmokers $(62.25$ percent) who reported dining more frequently outside NYC after the ban are in the smoke-tolerant group. As mentioned in point $\mathrm{D}$ above, the data do not permit us to state why anyone is dining outside NYC more frequently during the April to August period in 1995. Remember also that 34.4 percent of smoke-sensitive nonsmokers reported dining out more frequently in the months after the ban, and all smoke-sensitive nonsmokers avoid smoke-permitting restaurants.

\section{Cautions and Conclusions}

This response is our effort to clarify and set the record straight on the integrity of our study. What have been identified by the Evans Group critique as errors, flaws, unsubstantiated assumptions, and bias seem to be findings or data that do not support a particular position. It is easier to fault existing research when it conflicts with what you want to find than to conduct your own research. It is also possible that the aggressive critique is a reaction not to the study itself, but to the fact that the study is being used by contesting advocacy groups.

The Advocacy Institute is primarily concerned with public-health issues. In contrast, advocates for the tobacco industry (including the National Smokers Alliance) are interested in preserving the economic future of that industry. Both groups are sensitive to the economic impact on local restaurants, but have broader primary agendas outside the hospitality industry. We hope this response to the issues raised by the Evans Group and the NSA will provide some clarity for restaurateurs and encourage neutral researchers to consider extending this study. The study on consumer dining behavior was neither definitive nor flawed, it was simply the first of its kind. Now let's move on to new studies that help to refine and clarify this sensitive issue. 